\title{
Known for Unknown. Images from the Past for the Present Future ${ }^{\dagger}$
}

\author{
Luisa Chimenz * and Nicoletta Sorrentino * \\ Department Architecture and Design, Polytechnic School University of Genoa, 16123 Genova, Italy \\ * Correspondence: luisachimenz@arch.unige.it (L.C.); nicoletta.sorrentino@hotmail.it (N.S.) \\ + Presented at the International and Interdisciplinary Conference IMMAGINI? Image and Imagination \\ between Representation, Communication, Education and Psychology, Brixen, Italy, 27-28 November 2017.
}

Published: 20 November 2017

\begin{abstract}
In the very last years of the contemporary age, we are observing various processes that interest the field of design, particularly for what concerns product design, graphics and communication, and their development in relation to the historical matter. In such a situation, this impacts on the contemporary western society and on current trends in customs and tastes. However, it is actually not so incomprehensible, neither is a behaviour completely new. The meaning of a family air, the quid that adds a personal and significant value to an object and to a product is somehow indefinable but links the consumer, and maybe more the 'prosumer', strongly to itself, in a cross-process of personal and historical construction of narrative. In some artefacts history meets and talks to the stories: this is why we do love them.
\end{abstract}

Keywords: images of tangible and intangible heritage; collaborative images and imagination; design history; nostalgia and revival; retro and vintage

\section{Introduction}

Conducted during this last year, this research, still on-going, moves from a series of previous studies conducted, about the knowledge and the grasp of the history by the designers and consequentially on the influence that history could have on the approach and on the development of the projects within the design practice.

In this occasion, the issue is examined from a particular point of view, that involves aspects not only and not so much related to the practice of design, as the meanings that could be allocated both to the work and to its results.

In the very last years of the contemporary age in fact, we are observing various processes that interest the field of design, particularly for what concerns product design, graphics and communication, and their development in relation to the historical matter.

As we have already recently discussed [1], it seems happening something slightly incomprehensible at first sight: there is a turning back in time with styling, that looks like just one among the consequences of the intense strike of the routine and of the status quo, resulted by the effect of the financial crisis and of the hard geopolitical and social moment.

In such a situation, this impacts on the contemporary western society, and on current trends in customs and tastes. However, it is actually not so incomprehensible, neither is a behaviour completely new.

In fact, the reasons why there is and there has always been a turning backwards in time, and a change in orienting towards past trends the design choices can be the most diverse. Nonetheless, it could be possible explain these attitudes when they were observed in the past, thanks to the certain distance from which now we can look at it. By contrast, the evaluation of the contemporary context may be awkward and hard. 
Surely, history doesn't seem to have been forgotten; rather, what has changed is the way to refer to it, in a various conception of the flowing of the time, which is perceived and considered from a significantly different perspective, compared to what we were used to. Currently, the research of historical references keeps taking on the featuring traits of Post-Modernity, making the relationship with the time more and more emotional. In addition, the more the recourse to the style of past ages grows and increases, the more it seems to become effortless, almost skin-deep, targeted to awaken nostalgic memories. Talking about 'Historical imagination', Alessandro Mendini [2] (p. 51) already strongly stated at the time: «The planner belongs of fact to the world of the sentimental knowledge of the history. The optimal condition to steal historical styles and substance (to design in the state of historical imagination) it is gotten only through a romantic use of its complicated ingredients. Purified in its philological and scientific meaning, the history in itself it doesn't serve. Who designs can manipulate the history only if he violates it, if he pollutes it, linking it to his own personal history and of his fellow workers. The choice is among the cold 'history' and the warm 'memory', not being the memory anything else than the history referred to themselves».

More recently, in an interview regarding the relation between memories and emotions, Alessandro Bertirotti [3] highlighted how much of the current success of 'vintage' depends precisely on the feelings of distrust in the future, that are related to the crisis of the concept of society and alliance we used to know, and on the resulting sense of loneliness among people. Thus, the vintage becomes «a chance to reactivate an alliance among all these people that loved that product, that music, that fashion», and to feel protect again.

In this sense, the opposition of the terms 'Known' and 'Unknown' clarifies itself: on one hand, the present, and moreover the future, the fears for what is going to happen and on which we can't have control capacities. On the other one, the past, with its styles and manners, its old-fashioned shapes at which we look like into a golden mirror, able to recognize ourselves and to respond to an inner need.

Then, it could be said that the reference to the past is meant to recall, more or less consciously, values, memories, roots, in order to carry us back to a better time.

The reflection has been strongly inspired by the title "Immagini?", that presents a double layer of interpretation: it could be understood like a way to ask what kind of "Images?" are we talking about, as intended by the organisers of the conference. But it could be also interpreted as the question "Can you imagine?" that leads the discussion towards a different speculation again.

Somewhat, both these facets are to be considered, as necessarily images and imagination are tied up together, in the same way, images are related to the objects that determine them, with all these concepts together defining the one of 'imagery'.

\section{History Today: What and How}

In the sense previously expressed, as stated by Raimonda Riccini [4] (p. 19), «the imagery produces objects, as long as objects create imagery. Design established a historical key point, making this circular process its own main feature, its most important character: shaping the artefacts, and through this, making imageries existing».

Taking into account these considerations, the research has been developed examining some case studies, selecting among the most recent examples of product design, communication and graphics, the ones that could be considered emblematic of the attitude above explained.

Moreover, much food for thought on the issue arose from the activities undertaken during the Design History class, especially thanks to the results of the design exercise given to Product and Nautical Design students of University of Genova.

All this material has been the starting point for a wide range of considerations, involving the above history, style and imagery, but taking into account which meanings could be allocated to them, other than the poetical and sentimental ones, in the aim to increase the awareness about their impact on design and production processes on one hand, on the other on trade and consumption ones [5]. 
It is undeniable indeed that, as stated by Thomas J. Watson, "Good design is good business": any surprise, therefore, if from a merely economical perspective, the investment on something already done successfully in the past keeps looking reasonable and relatively sure.

In case of redesign of products of the past, the success in following this path lies in the response of the consumers, in front of a new product expressly designed to recall from memory emotions and affection.

In a large part, it strongly depends on the success of its forerunner; remaining on the address of the topic, it could be said that it depends on how much the original was known and loved, in other words, how much its shapes and its image were not only useful, functional and beautiful, but also they were that way so much to fix themselves in the history of a country, becoming part of the imagery of a society, and then of its 'culture' intended «as the shared values of a community», in agreement with John Heskett [6] (p. 31).

It's what has happened with one of the most famous objects throughout the world, the Italian city-car Fiat Cinquecento: considered an icon of the Italian Good Design, its picture immediately takes us to a particular moment in our history, embodying all the significance of that period. On the 60th anniversary of the release, the Museum of Modern Art in New York announced the acquisition in its permanent collection of the Fiat Nuova Cinquecento designed by Dante Giacosa, enshrining so its importance and meanings.

At the same time, Fiat released the last versions of Nuova 'Nuova Cinquecento' (first issue in 2007 by Roberto Giolito), in a special series and a limited edition call Anniversary, to celebrate this important goal in the history of the company. Particularly, they include two new colours for the bodywork and some details which are straightly inspired by the original ones of the 60 s, enhancing the already accentuated retro look of the car (Figure 1).

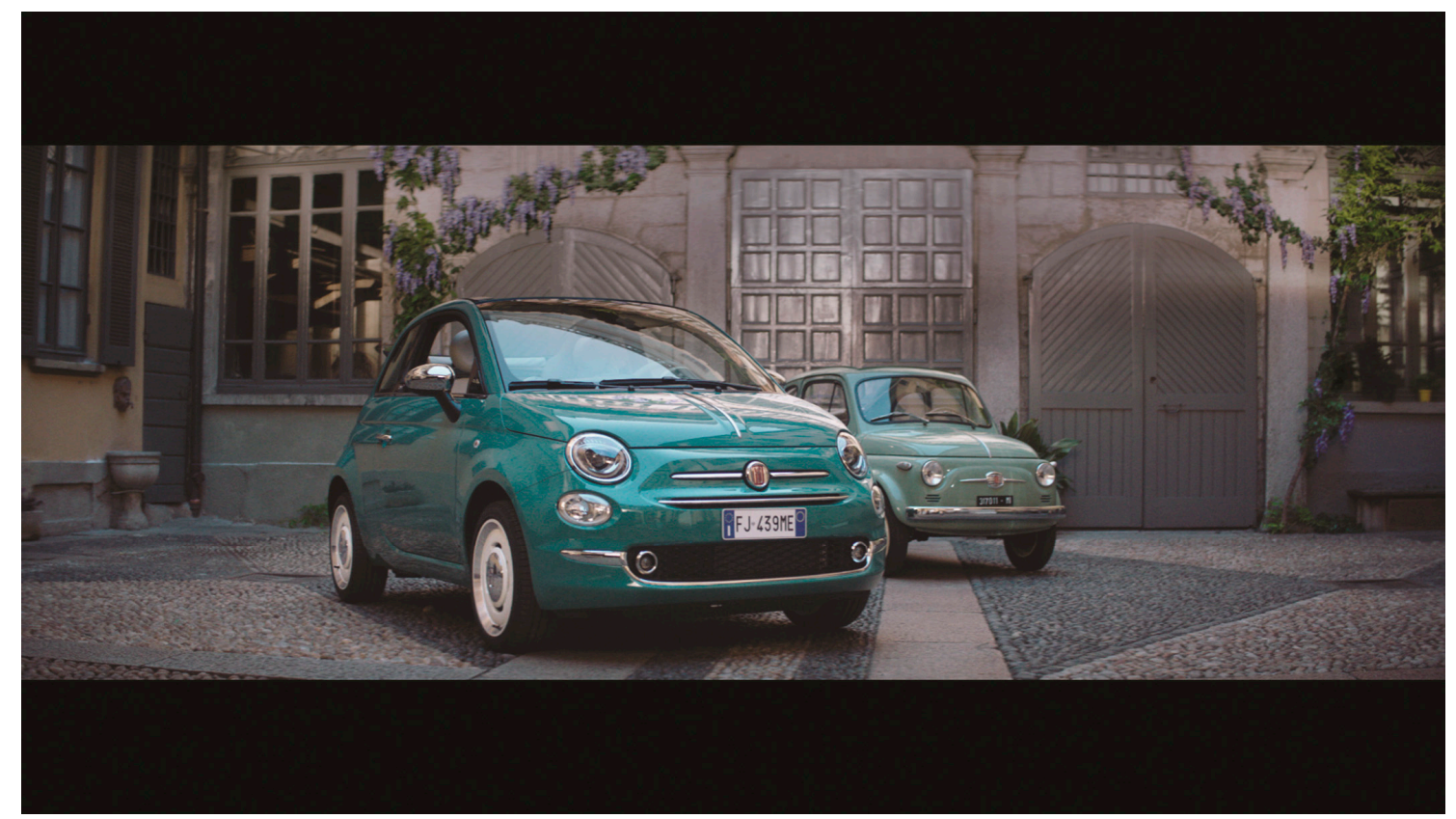

Figure 1. Original and new Fiat Nuova Cinquecento in a frame of See you in the future.

In this complex set of cross-referencing and occasions, it is furthermore of special interest for this research the celebrating short movie See you in the future, with the Oscar-winning actor Adrien Brody (Video S1).

Realized by the ad agency Leo Burnett Italy and directed by Ago Panini, the extended web version tells a story in which classic themes such as love, beauty and dream create a bridge between the past and the future, making possible even the most extraordinary impossible. In a romantic atmosphere, thanks to the allure of the characters and to the accurate settings, the old and the new meet together to talk about a car that now has grown up and is no longer the affordable vehicle once 
it was, but is the most 'stylish' that you can buy. Moreover, this car allows who owns and drives it to feel like living in a dream, or even in the Dolce Vita.

In this sense, once again «industry of Italian design, thanks to its products and communication [...], has contributed to build a popular imagery, in which concepts such as utopia, hope, future, freedom and beauty strengthen the essential usefulness» [4] (p. 14). Last but not least, the issuance of the commemorative stamp of the anniversary: all the meanings and the significances above expressed summed up in a single image.

Another design recalling lines and shapes of the past is the sofa $F A V N$, designed in 2011 by Jaime Hayon for Fritz Hansen (Figure 2). Clearly less fraught with emotional values compared to the previous one, it is the transposition in the contemporaneity of a well-known speech. In the intentions of the author, expressly «FAVN is picking up from the long tradition of Arne Jacobsen in the sense that I wanted to create a form that was based on a shell, like the $\mathrm{Egg}^{\mathrm{TM}}$ and the Swan ${ }^{\mathrm{TM}}$ which looks equally beautiful from all angles» [7]. Like others seats signed by the author for the same company, actually, this sofa arises in dialogue with the historical masterpieces designed by Arne Jacobsen about sixty years ago, thanks to the shared "grammar" composed of rigid shells and soft paddings, in order to create welcoming and embracing organic elements.

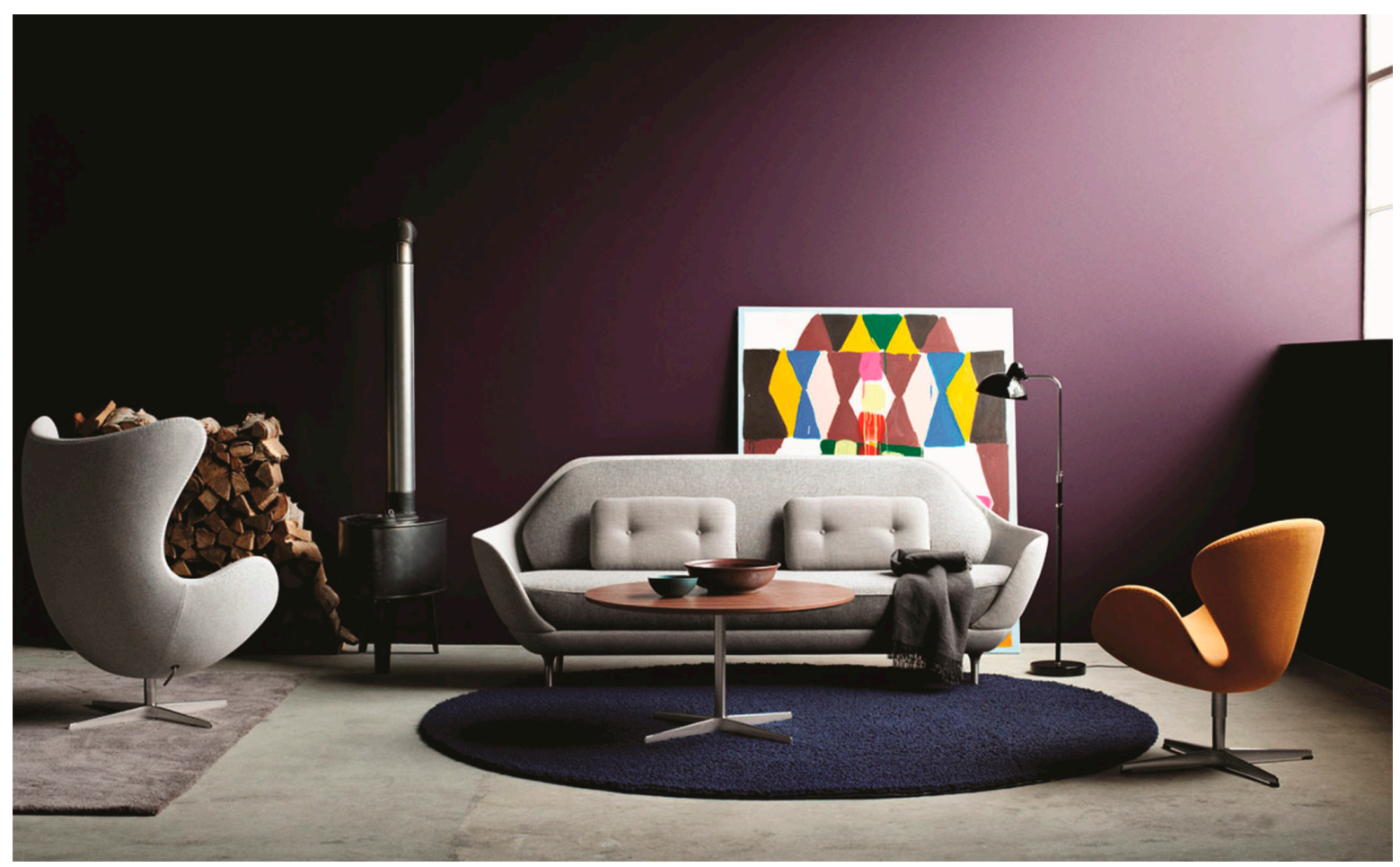

Figure 2. FAVN sofa by Jaime Hayon (2011), with Egg and Swan chairs by Arne Jacobsen (1959).

Finally, as anticipated above, the exercise assigned as part of the Design History course of which we are responsible gave us many opportunities to reflect on the awareness and the competence on history acquired by the students, obviously taking account of their young age as persons and, even more so, as designers.

The exercise consisted in imaging an interior of their choice, wherein include designs selected among the projects presented in the class, in order to create an ambience consistent as much as possible with the theme developed. This orienting to a project address has pretty changed the course, otherwise more theoretically featured. As a result, on more than one occasion the evaluation of the exercises revealed a surprising grasp of history, and moreover the ability-obviously to be increased-in mixing and combining projects of different ages and geographical contexts. Could it be a consequence of these new generations of designers growing up in such a present moment, so close to its past to the point of sometimes forgetting the distance from it, bringing back objects and languages without replacing them in historical perspective? History can actually become a gold 
mine, an inexhaustible source of inspiration, from whence learn lessons for our projects. The main question is if this kind of attitude could hide the risk of sublimation of the past and refusal of the present: in terms of design practice, if walk down the easiest way merely "copying" from the past to maximise profits, or increase our responsibility becoming more conscious of the legacy we are leaving behind.

\section{History Today: Why and Where}

As already briefly presented in the Introduction of this essay, we might observe that in periods of financial crisis and maybe more impacting extensive social changes, within a general climate of uncertainty, the turning back to the past is deeper and sturdier. Bassi, on the topic, says [8] (p. 68):

«In a phase of increasing economical, social and cultural uncertainties, the offer of products is oriented through the assimilability to reassuring aesthetical and typological criteria; a sort of heterogeneous homogeneity, of difference in the uniformity. This is connected with the so-called 'design of memory' that, leveraging even on the dynamics linked to objects of affection, proposes products inspired to the recent past with which it is uncomplicated to get tuned».

Bassi explains how and why the process is so evident in car design, naming the already cited Fiat 500, but even the Volkswagen New Beetle and the Mini. He continues [8] (p. 68):

«Besides the products with the taste of 'memory', also modern antiques and design collecting perform a similar reassuring function, but especially the re-edition or the maintenance into production of historical 'evergreen' pieces with the aim of rediscovering values, meanings and qualities hard to be identified in the current scenario. An operation somehow even nostalgic, that ends up transforming the icons of the past in pure image».

Orth and Bourrain, in their essay, here loaned and reported from the field of marketing, say that [9] (pp. 277-278):

«Few studies have linked evoked nostalgic memories to consumer behaviour, and all of those were conducted in an advertising context. Details of whether or how nostalgic memories actually work in a retail environment remain largely unknown. Even initial evidence is not available on this question, i.e. from experiments in controlled environments that could extend the literature in a manner beginning to address implementation. This study examines effects of scent-induced nostalgic memories on consumer exploratory tendencies. It integrates past findings that nostalgic memories generate a variety of strong emotional-motivational responses and suggestions that consumer exploratory tendencies are driven by both consumer sensation seeking states and personality rather than by the personality alone».

In particular they are addressing their interest to personal memory, and so personal nostalgia, but we believe that History as an acquired heritage can be considered properly as a factor of both collective and personal nostalgia.

Moreover we wish to support our idea with Heskett's words stating [6] (p. 37):

«Objects are a crucial expression of ideas of how we could or should live, put into tangible form. As such, they communicate with an immediacy and directness that is not just visual, but can involve other senses. [...] Such diversity in how objects are conceived, designed, perceived and used also provides multiple perspectives from which they can be understood and interpreted».

How it has been shown in Brown and Sierra \& McQuitty [10,11], it is true that this 'nostalgia factor' interests, or it may do, all products and so all domains of design. Confidently, furniture design products and little home accessories tend to respond as very performative media for bringing a 'touch' of history in contemporary private and public landscapes as it, maybe, can be seen by Tacchini's screens, blending English contemporary design, French original Art Déco decoration, and Italian heritage in a dense accessory referable to many inheritances (Figure 3).

Basically brands and firms display to know this process, as stated even by Savino, Messeni Petruzzelli and Albino [12] (p. 41):

«In this scenario, in addition to the well known and recognized importance played by technological innovation, firms may face competition exploiting tradition, viewed as the collections of cultural elements that may include symbols, material objects, myths, custodians, rituals, temporal 
qualities as well as collective identities and memories. Specifically, a firm may use tradition as a distinctive resource both to create value as well as to capture it. In fact, traditions are repositories of elements through which it is possible to evoke collective memories, identities and social cohesion.

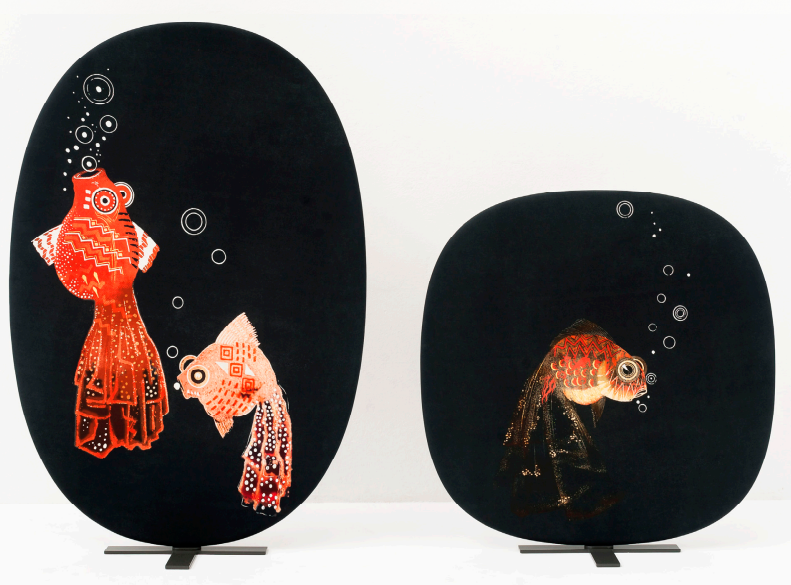

Figure 3. Nebula Poissons Textiles with Jean Dunand décor by Pearson \& Lloyd (2017), by Tacchini. Ph.

Andrea Ferrari, on Tacchini's official website.

Hence, the usage of tradition allows to characterize products with elements strictly tied to a specific firm, territory, and/or age in order to overcome homogenization. Accordingly, a competition based on tradition implies also to re-think globalization processes, shifting from the "think global, act local" model, which emphasizes the importance of global best practices, to "think local, act global", which aims at globally promoting local differences and peculiarities».

Tradition, heritage, nostalgia, values: we dress all these words in the veils of time, not so attractive to a young consumer as a first sight might let to think: indeed, in design history, and in historical-referable products and graphics there find place the statements of a self-expression, only apparently weaker than a more puristic contemporary one. It is the case for instance of LUSH brand, choosing for its campaign of sustainable products self preserving and historical English-inspired graphic, quoting - in our opinion-Owen Jones, his studies and in particular the work presented in his book, The Grammar of Ornament. Charlotte Day, the designer, expresses through her graphics the naturalness of the ingredients and at the same time she declares in her style where she comes from (Figure 4). Lush is applying what Savino, Messeni Petruzzelli and Albino, in fact, express in their essay as an interesting concept-yet again borrowed from the business aspect of the issue, here wishing to demonstrate that all these features convey their interest in products as goods and items for consumption, [12] (p. 41):

«Creating value through tradition may be achieved using both traditional technology and design, applied at product and/or process level. However, to fully exploit the benefits arising from traditional elements, firms have to capture the created value, developing an idiosyncratic link between products and processes, and the image and identity of the firm, which has to reflect in its organizational routines the tradition it employs». 


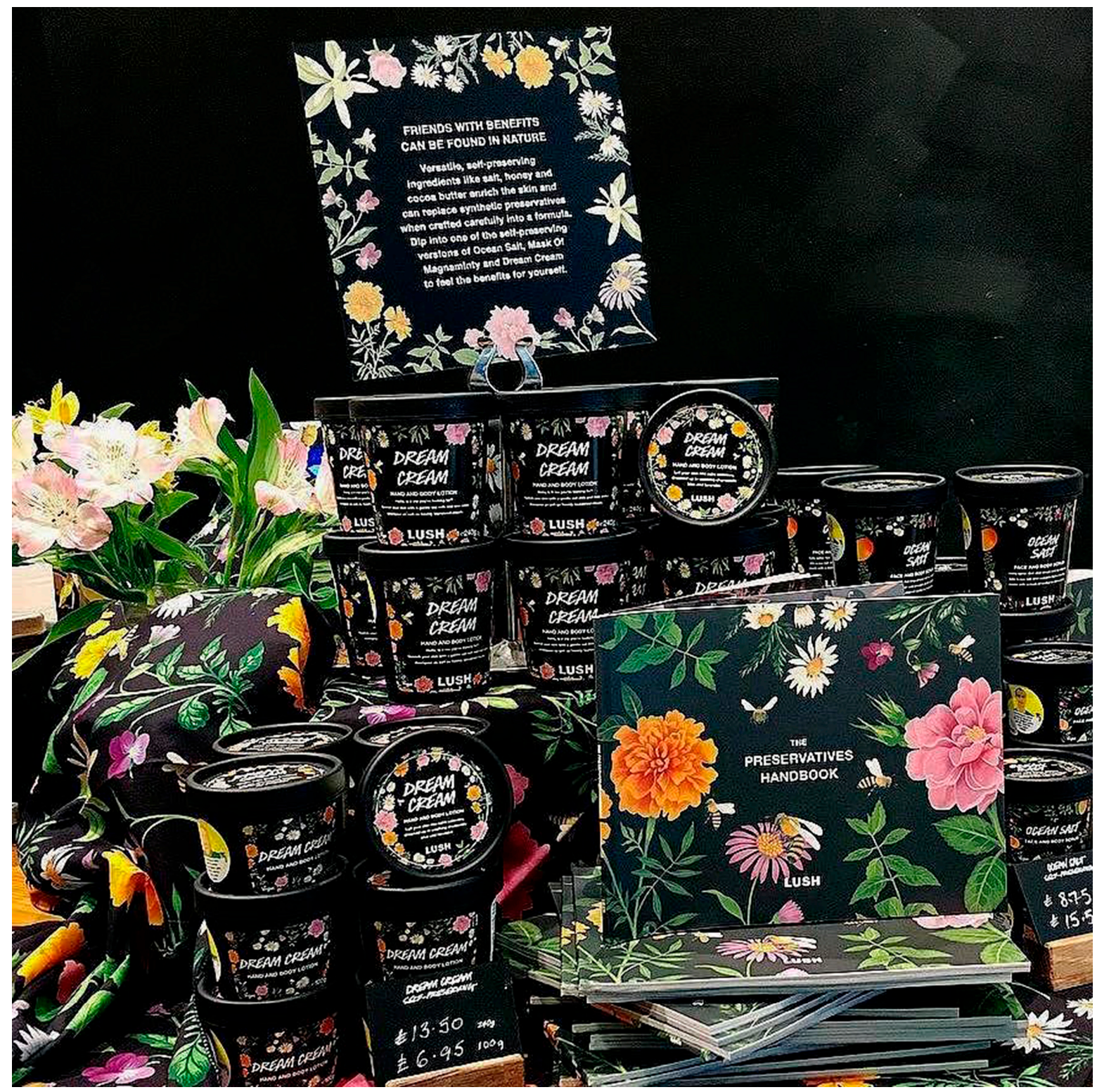

Figure 4. Charlotte Day, LUSH Self preserving campaign, 2017. The graphic designer on her Twitter page, on May 14th, announcing the releasing for new potties with her illustration.

An interesting aspect that might clarify the choice of such this strategy in design and in production may be largely introduced by the words of Veenstra and Kuipers, in their essay about vintage and the impact that this has on contemporary fashion [13] (pp. 3-4):

«Vintage is promoted as exclusive and authentic replacing contemporary haute couture, as 'a sign of individuality and connoisseurship'. Koontz (2010) identifies two forms of authentication in search for 'real' products in consumer society: 'otherizing' and 'traditionalizing'. Otherizing uses the mainstream as referent, defining subcultural, foreign or minority products as 'the authentic other'. Traditionalizing consists of five aspects, three of which characterize vintage. The first entails hands-on and personalized 'production methods'. The second is 'constructing nostalgia': idyllic products are adapted to contemporary consumer desires. The last, 'replicating original formulas', concerns replication of authentic products. The ideal of authenticity is thus not exclusive to vintage wearers. Rather, the ideal of authentic products has become the norm in contemporary society. Accordingly, authenticity is the result of negotiation and tension between (mass) production and (individualist) consumers».

In the product design ambit it is dissimilar, actually: my original Wedgwood, even if issued in 2017, tells about decades of elegance and at the same time of such a richness in culture and wealth 
(despite of being much more affordable than on original dated Wedgwood, even if not so affordable compared to an IKEA item). Thus, in this manner, is comprehensible Lee Broom's appointing for a limited collection in jasperware: if the designer for one hand recognizes the heritage beyond the commitment, on the other expresses in his creations the combination with post-modern twist, at the same time allowing usability and easier production [14].

Shifting again to the vintage matter, Veenstra and Kuipers continue [13] (pp. 12-13):

«Vintage communicates and expresses a longing for an authentic identity that is informed by a sense of nostalgia. While vintage distances itself from mainstream consumption culture, it does not 'rebel' against society, nor does it explicitly 'subvert' items that are offered by mainstream consumer culture. On the contrary: through accumulating garments that are not recently produced, or (homemade) productions in limited numbers, the commercial producer is initially brushed aside. Rather than subverted, contemporary consumer culture is surpassed or overtaken by vintage consumption practices. This implies that vintage deploys the logic of consumer culture: it performs identity through consumption. [...] Nostalgia found its way into material culture, expressed through vintage».

This is almost what happens in fashion as for the vintage in the opinion of the scholars, in fact, differently from the design field and far from our point of view they state [13] (pp. 3-4):

«Existing studies connect vintage with authenticity, nostalgia and identity. [...] Accompanied by an unsentimental nostalgia, vintage is neither concerned with the sanctity of tradition nor with a conservative reinforcement of cultural (gender) values».

In an artefact's design the nostalgia, the revival in forms and the retro-shaping of products is never unsentimental. On the contrary, there is a precise and strategic vision for recalling, reminding and remembering, as even expressed by Russo [15] (pp. 51-53).

So, maybe, it works even in a stronger manner in a (properly) historically-based design: it is and states a re-appropriation of the whole period, lifestyle, a imagination quoted, indeed. Again mentioning Veenstra and Kuipers, in fact, and reporting literally their research results to our domain we may say, quoting their words [13] (p. 6):

«As social mobility increased, education became more accessible, globalization set in, individuals experienced an increasing freedom to shape their lives as they pleased. Consumption became central to this construction of identity. [...] Appearances increasingly function as an external reflection of the best possible self. If not properly maintained the result is a lowering of one's acceptability as a person. In late modernity this best possible self is increasingly performed through consumption. The choice of lifestyle in contemporary consumer society is to be read as the individuality of taste and sense of style of the owner/consumer».

This last concept perfectly introduces our personal observations and conclusions, which in this essay are centred more on the consumer's side, while elsewhere the reason of why and where this kind of strategies and design experience is skilled from the designer's point of view is treated [1].

\section{Conclusions}

For better defining which is our idea of style and its relation with images in this case related to the past, as a further explanation of what said in the Introduction of this essay, it appears proper to quote Falcinelli saying [15] (p. 275):

«Style is the constant appearance that we identify in things, events, behaviours. It is the sensation of identifying, through appearances, a homogeneous imprint that gathers different phenomena. It is a family air, an esthetical quid. Style isn't defined, it is recognized».

The meaning of a family air, the quid that adds a personal and significant value to an object and to a product is somehow indefinable but links the consumer, and maybe more the 'prosumer' [16] (p. 91), strongly to itself, in a cross-process of personal and historical construction of narrative. In some artefacts history meets and talks to the stories: this is why we do love them.

The turning back to the past, the search for an inspiration in it, maybe renovating and re-interpreting it according to nowadays product requirements, is a good exercise for a designer, the adoption of a paradigm, we may say. Perhaps, more interesting are the selections that are made by 
the users, which naturally and basically embed the product at a first glance with all their personal and cultural background in a non-revertible process.

As a further acknowledgement of the matter of personal identity expression, through the use of the past in contemporary products, we may translate from fashion design the concept expressed by Veenstra and Kuipers in their essay about vintage's selection as an expression of (sub)culture [12] (pp. 3-4):

«In their rejection of new (mass-produced) design, vintage items symbolize uniqueness and authenticity: a distinctive individual look that is worn by nobody else. This aesthetic preference for authenticity, expressed through vintage, has become a broader (mainstream) preference».

Accepting to broaden this type of behaviour to other designed items for consumption, we need to recognize that if it is maybe easier to find vintage fashion, somehow original furniture and pieces are still unaffordable for the most, being today incredibly more expensive than in their date of issue. So, the referral to the past helps us to accomplish our nostalgic and cultural afflatus of aesthetical, yet affordable, artefacts.

In fact, Orth and Bourrain observe that [8] (p. 278): «It is argued that nostalgic memories may exert an important influence on consumer sensation seeking states with downstream effects extending onto consumer exploratory tendencies and behaviours».

We already clarified that referring to the concept of nostalgia we are looking to the past, wearing somehow, consciously or not, rose sunglasses which make everything softer, brighter and - of course - nicer. In fact, Veenstra and Kuipers say [13] (p. 7):

«Contemporary societies are structured by accumulation of experiences, reflecting the pattern of consumption that both identifies and communicates to what group one belongs. Personal style then not only expresses identity, but also communicates this identity to others. Moreover, by communicating what to expect, style structures experiences».

If making "beautiful and well-done" is a general must for designers [17] (p. 85), according to Trabucco we might agree that furniture pieces are like «objects of affection, on which is built and soaked in the intimate and emotional experience of the everyday life». This is why some, consecrated by time as icons, arrive to us almost untouched and generate re-editions and new designed artefacts, imposing themselves as ultimate referrals.

Accordingly, Heskett, on the relation that interwoven objects and the reasons for which we choose them, states that [6] (p. 84):

«Objects and environments can be used by people to construct a sense of who they are, to express their sense of identity. The construction of identity, however, goes much further than as expression if who someone is; it can be a deliberate attempt by individuals and organizations, even nations, to create a particular image and meaning intended to shape, even pre-empt, what other perceive and understand».

It's worth to accept it: in highly historical-referred products we found ourselves, our nearer or farther roots, our identity, as it is or as we wish it to be. Producers and designers are giving us a choice, a possibility: we, as consumers, make our own ones and build our narratives, these latter for how we want people to perceive as true and adherent to ourselves. By choosing and displaying, in our personal and public environments, these types of artefacts we are stating our identities and affirming our sense of belonging, showing and presenting them to the crowd.

Supplementary Materials: The following are available online at https://www.youtube.com/watch?v=ZxcxSNLvV0Y. Video S1: Leo Burnett Italy (Executive producer), \& Panini, A. (Director). (2017). See you in the future. Italia: Movie Magic (accessed on 15/09/2017). More about self preserving products campaign by Lush, with Charlotte Day's graphics and Owen Gildersleeve set design can be found on Vimeo at https://vimeo.com/208645486 Video S2: Owen Gidersleeve (set design). (2017). LUSH: Self preserving. YCN (accessed on 15/09/2017). Figure S1: The images of FIAT Nuova 500 and Nuova 'Nuova 500' are available online at http://www.sportfair.it/wp-content/uploads/2017/07/fck.jpg, Figure S2: The image of Sofa Favn is available online at https://hivemodern.com/public_resources/full/arne-jacobsen-swan-chair-fritz-hansen-12.jpg, Figure S3: The image of Nebula Poissons Textiles designed by Pearson \& Lloyd London-based studio and decorated with Jean Dunand's dècor is available on-line in high resolution, photographed by Andrea Ferrari, at http://www.tacchini.it/it/nebula/148/prcd.php; Figure S4: The image of self-preserving LUSH products and 
campaign, in the displayed catalogue is retrieved from Charlotte Day's twitter page, available at https://twitter.com/CharlottePaints/status/863697783454408704, Figure S3.

Acknowledgments: We wish to acknowledge the Conference Organizers for giving us the possibility to present this essay and the on-going connected research work. We also recognize the contribution of anonymous reviewers for improving this manuscript and we take the opportunity to thank as well the authors of cited books and articles for inspiring us and helping us in sustaining our ideas.

Author Contributions: Within the whole work here presented Nicoletta Sorrentino wrote "Introduction" and "History today: What and How", while Luisa Chimenz wrote "History today: Why and Where" and "Conclusions". The research here presented and the concept beyond this work is directly and equally divided between the two authors, even if, an anticipatory essay has been published in the month of February 2017 by Luisa Chimenz in the cited publication [18].

Conflicts of Interest: The authors declare no conflict of interest.

\section{References}

1. Chimenz, L.; Sorrentino, N. Welcome back. Retro and revival, heritage and vintage: Presence of the past in contemporary design processes. In De-Sign. Environment Landscape City; Pellegri, G., Ed.; David \& Matthaus: Serrungarina (PU), Italy, 2017; pp. 413-423, ISBN 978-88-6984-109-5.

2. Mendini, A. La Poltrona di Proust: Architettura, Arte, Design e Altro; Tranchida Editore: Milano, Italy, 1991; ISBN 88-856-8552-8.

3. Bertirotti, A. (2017) Alessandro Bertirotti: Dreaming an Emotions-Driven Future. [interview by Nefula]. Available online: http://nefula.com/conversation/alessandro-bertirotti/ (accessed on 15 September 2017).

4. Proverbio, P.; Riccini, R. Design e immaginario. Oggetti, immagini e visioni fra rappresentazione e progetto; Quaderni IUAV Il Poligrafo: Venezia, Italy, 2016; pp. 9-16, 19-36. ISBN 978-88-7115-940-9.

5. De Fusco, R. Storia Del Design, 6th ed.; Laterza: Roma-Bari, Italy, 2005. ISBN 88-420-6623-0.

6. Heskett, J. Design. A Very Short Introduction; Oxford University Press: Oxford, UK, 2002; pp. 1-54, 84-141. ISBN 978-0-19-285446-9.

7. Republic of Fritz Hansen. Embraced by Favn ${ }^{\mathrm{TM}}$. Press Release 2011. Available online: http://downloads.fritzhansen.com/asset-bank/action/viewAsset?id=5679 (accessed on 15 September 2017).

8. Bassi, A. Design Contemporaneo. Istruzioni Per L'uso; Il Mulino: Bologna, Italy, 2017; pp. 7-13, 46-123, ISBN 978-88-15-27070-2.

9. Orth, U.R.; Bourrain, A. The influence of nostalgic memories on consumer exploratory tendencies: Echoes from scents past. J. Retail. Consum. Serv. 2008, 15, 277-287, doi:10.1016/j.jretconser.2007.06.001.

10. Brown, S. Are we nearly there yet? On the retro-dominant logic of marketing. Market. Theory 2007, 7, 291300, doi:10.1177/1470593107080348.

11. Sierra, J.J.; McQuitty, S. Attitudes and Emotions as Determinants of Nostalgia Purchases: An Application of Social Identity Theory. J. Market. Theory Pract. 2007, 15, 99-112, doi:10.2753/MTP1069-6679150201.

12. Savino, T.; Messeni Petruzzelli, A.; Albino, V. Searching in the Past. Strategic Approaches: Creating and appropriating value through tradition. In Integrating Art and Creativity into Business Practice; Schiuma, G., Lerro, A., Eds.; IGI Global: Hershey, PA, USA, 2016; pp. 40-54, doi:10.4018/978-1-5225-2050-4.

13. Veenstra, A.; Kuipers, G. It is not old-fashioned, it is vintage. Vintage fashion and the complexities of 21st century consumption practices. Sociol. Compass 2013, 7, 355-365, doi:10.1111/soc4.12033.

14. Sissons, J. Lee Broom's New Limited Edition Ceramic for Wedgwood, 5 April 2017. Available online: https://howtospendit.ft.com/house-garden/200470-lee-broom-unveils-his-limited-edition-ceramics-for-we dgwood (accessed on 4 September 2017).

15. Russo, D. Il Lato Oscuro Del Design; Lupetti: Milano, Italy, 2013; pp. 43-53, 57-80, ISBN 978-888391-335-8.

16. Falcinelli, R. Critica Portatile Al Visual Design. Da Gutenberg Ai Social Network; Einaudi: Torino, Italy, 2017; pp. 3-11, 275-302, ISBN 978-88-06-21771-6.

17. Trabucco, F. Design; Bollati Boringhieri: Torino, Italy, 2015; pp. 11-40, 75-135, ISBN 978-88-339-2663-6.

18. Chimenz L. Il valore della storia nel progetto contemporaneo. In Psico-antropologia per il Design; Bertirotti, A.; David and Matthaus, Serrungarina (PU), Italy, 2017; pp. 315-333, ISBN 978-88-6984-158-3. 